\title{
Research on Cost Management of Construction Project based on Activity-based Costing
}

\author{
Jianqiang Tang, Maoping Zhang, Hua Tang, Yuan Chen \\ Department of Management science and Engineering, Sichuan Agricultural University, Chengdu,610000, China
}

\begin{abstract}
This paper, based on the principle of activitybased costing, mainly introduced the specific process of applying the method in cost accounting and cost forecasting during the Project Construction being constructed. Through using the activity-based costing to calculate the actual cost and the budget cost in the process of project construction, which to be compared to analysis the cost deviation, while predicting the material supply-demand relationship of next issue. Furthermore, in the light of the deviation, reengineer the process of project construction and adjust resource supply level, thereby effectively refine and control costs, improve management and competitiveness of project contractor.
\end{abstract}

Keywords-activity-based costing management, the process of project construction, Cost, Control.

\section{INTRODUCTION}

Facing with the current state of regulating the real estate market, the slowdown of the economic growth, the rising of rigid cost, inflationary pressure, and deflation of credit policy, etc. the competitiveness in the construction industry mainly shown at price competition, competition has become increasingly fierce. Therefore, a kind of good cost management in the fierce competition in the industry is particularly important.

Activity-based costing as a method which plays an important role in manufacturing industry, has been relatively widely used and researched since the early 1990s[1]. By reading a lot of relevant literatures, found that scholars like Rui Zhang[2], whose studies mostly focused on the application of activity-based costing in manufacturing industry. Liang-Hai Lei[3]analyzed the necessity and applicability of the activity-based costing in the valuation and mortgage company of real estate, based on the characteristics of the valuation and mortgage company of real estate company built application model of activity-based costing in the valuation and mortgage company of real estate company, Gui-Wen Liu[4] proposed three notes in the process of applying activitybased costing in real estate development, Yi-Jian Sun[5]focused on the problem in the process of real estate development, on the basis of activity-based costing, built a dynamic cost management model of real estate, after analyzing the shortcomings of traditional cost management methods, but did not do more in-depth research and analysis. This paper under the project contractor perspective, proposed construction cost management research project based on activity-based costing.

\section{THE PROCESSES OF DYNAMIC COST MANAGEMENT OF CONSTRUCTION PROJECT}

Activity-based costing is a kind of cost accounting method[6]whose core concept is "products consume activities, activities consume resources"[1][7][8]. Activity-based costing is detailed by Robin Cooper. It is a new method of cost management which is activity oriented and calculates the cost of products by confirming the activities in the process of construction project and measuring the cost of activities.

Compared with traditional cost accounting methods, activity-based costing has changed the situation in the past that only rely on a single operation measuring index, such as working hours, the number of equipment and so on, but using a multi-dimensional distribution pattern, which reduce the deviation between the accounting costs and the actual cost and is seen as an effective management method, to enable enterprises to be more competitive by achieving the purpose of the enterprise value-add from the perspectives of the process and the value chain.

Costing analysis in the process of project construction based on activity-based costing is the application of the basic principles of activity-based costing. By analyzing every activity that occurred in the course of the project construction, establishing activity database and according to the consumption of resources that activities has taken, trace the resources back to the activities, and then, in accordance with the consumption of the product for the activity, calculate the cost of products, besides, on the basis of scientific computing product cost, this method has taken the other costs of the project which previous studies have ignored into account. Therefore, the actual cost of the constructed project can be reasonably calculated, and then making the appropriate adjustments based on the deviation between the actual cost and the budget cost, which is aiming to improve project management level.

This is a dynamic loop cost management process. When labor and resource are put into the process of project construction, cost accounting can be carried out according to the activity-based costing. At the same time, under the premise of reasonable analyzing the yield of construction products of buildings in the next issue, applying inverse operation of the activity-based costing to predict the resource consumption of the next cost control interval, and then to predict the actual cost of the entire project for the future, in order to achieve the appropriate project cost management objectives and financial indicators, thus to analyze the production capacity and 
non-value-added activities of the project, and putting forward corresponding management recommendations.
The technical route shown as figure 1.

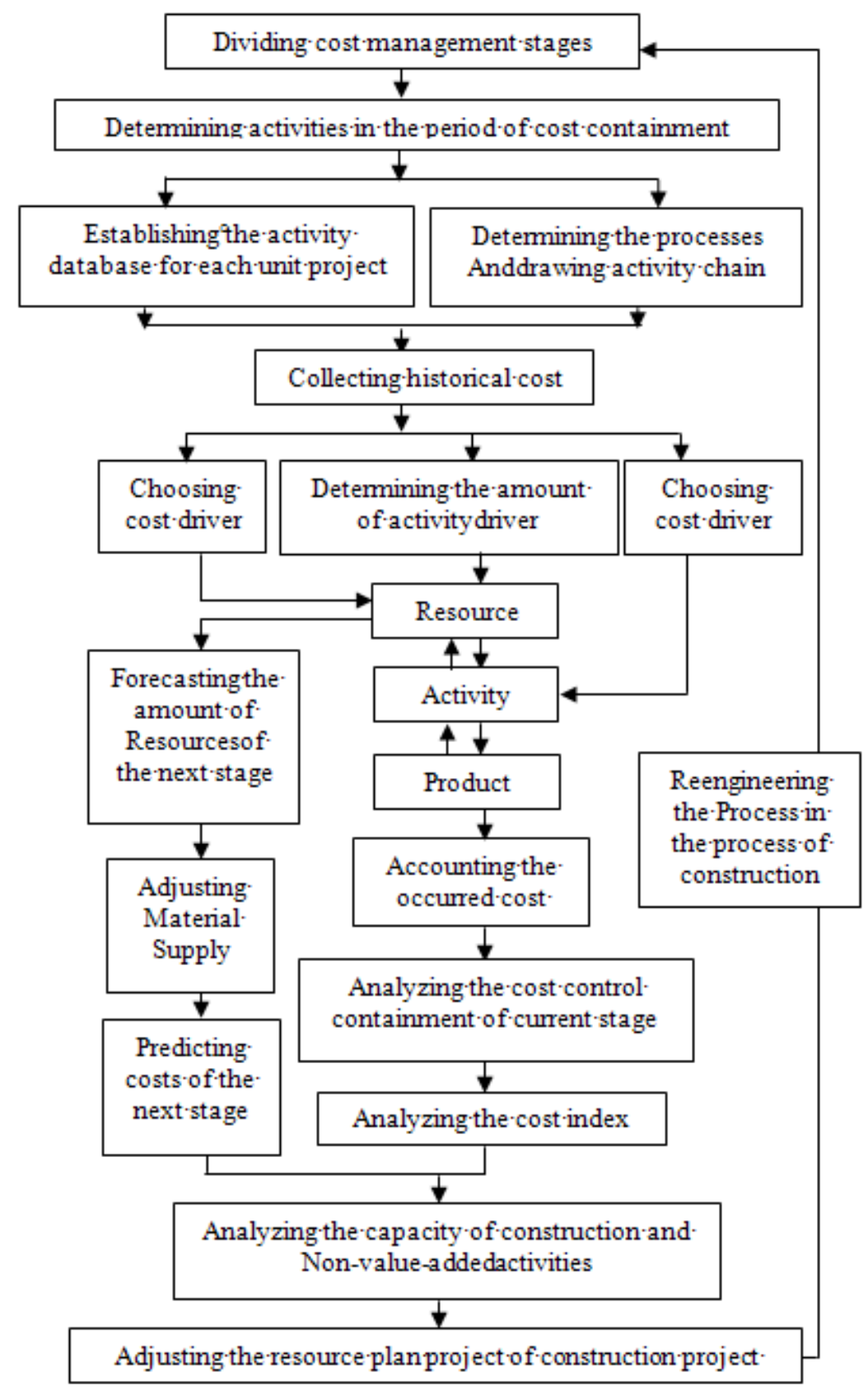

Figure.1:The technical route

III. SPECIFIC IMPLEMENTATION STEPS OF DYNAMIC COST MANAGEMENT OF CONSTRUCTION PROJECTS

Before cost accounting, the project managers have to divide the project into different stages of cost management, and fully analyze all the activities during each stage of construction project, on the basis of the historical experience, effectively and completely determine all the activities and confirm activities by integrating and decomposing the activities eventually of various stages, and then analyze and determine the cost accounting system on the basis of amount of recent data. There are six summarized steps to together constitute a recyclable cost management of the construction project 


\section{A. Dividing cost management stages of construction project and establishing cost accounting system}

Project construction can be roughly divided into several construction stages, such as the earthworks, foundation, masonry structural engineering, concrete structure project and so on. After dividing cost management stages of construction project in terms of the different construction stages, develop appropriate project cost plans according to different stages of management objects, and then make clear goals of project cost management at different stages, separate the budget in accordance with project plans into each stage of dynamic cost management. At last, establish cost accounting system in terms of the principle of construction enterprise accounting.

\section{B. Collecting historical resource costs and determining activity drivers}

Through analyzing and summarizing the financial data of construction projects, integrate and decompose the historical data of finance on the basis of empirical method to determine the process and activities in the process of construction, to identify the key activities and the activity chain, and to establish activity centre. For example, concrete engineering are generally divided into reinforcement engineering, form work engineering and concrete engineering, the activities and activity chains of these three projects go as follows: Concrete engineering: aggregate crushing $\rightarrow \quad$ sieving $\rightarrow \quad$ washing $\rightarrow$ proportioning $\rightarrow$ mixing $\rightarrow$ pouring $\rightarrow$ maintenance; Reinforcement engineering: checking the type of reinforcement $\rightarrow$ making construction plans $\rightarrow$ installing reinforcement; Formwork engineering: making formwork $\rightarrow$ positioning $\rightarrow$ formwork erection $\rightarrow$ separating formwork $\rightarrow$ repairing formwork.

The activity driver includes the cost driver and the resource driver. Cost driver, that is selecting criteria of allocating costs of each activity center, is more difficult to be determined between cost driver and resource driver, and every activities cost database should select a cost driver that reflects the consumption of activities during the project construction and have a high degree of correlation. Do not use the cost drivers that inaccurately or wrongly reflect the consumption of activities. For example, setting formwork engineering as a cost database, the cost driver is the area that construction project requires during the formwork.

\section{Establishing activity lists, determining the amount of cost drivers and accounting the cost}

The amount of cost drivers is the basis of allocating the total cost expense. Whether the amount of cost drivers is accurate determined or not, directly affect accounting and predicting the total cost expense. The amount of cost drivers in project management specifically refers to the amount of the cost drivers that the construction products consumed. Compared with the traditional method to gain the amount of the cost drivers according to collecting and classifying the relevant original records and analyzing with experience, the method given in this article to get the amount of cost drivers through establishing activities lists in the process of construction project, makes the amount of the cost drivers more detailed and accurate, and can reflect the resource and cost consumption better.

Accounting the current project costs based on the basic idea of "activities consume resources, products consume activities". Determine and measure the total amount of the resource driver of different resources that all goods consumed according to the established activity list. And then directly gain the current costs of each activity through the currently established resource base. The equation is as follow:

$$
A C_{i}=\sum_{k=1}^{n} R C_{k} \times R D N_{i k}
$$

In this equation, $A C_{k i}$ represents the costs of the number $i$ activity, $R C_{k}$ represents the number $k$ resource that the number $i$ activity consumed, $R D N_{i k}$ represents the amount of the resource drivers of the number $k$ resource that the number $i$ activity consumed.

According to the calculations above and the idea of "products consume activities", the cost of each activity is distributed into different construction products like girders and column, according to the established cost database of activities and determined activity divers. The activity driver is the standard of

cost allocation, and the way to allocate costs of activities in this article is based on the result of selecting cost drivers under the empirical method. The allocation equation is as follow:

$$
U P C_{k}=\sum_{k=1}^{n} A C_{k i}=\sum_{k=1}^{n} \frac{A C_{i}}{\sum_{i=1}^{m} A D_{k i}} \times A D_{k i}
$$

In this equation, $U P C_{k}$ represents costs of the number $k$ unit project, $A C_{k i}$ represents the assigned costs of the number $i$ activity in the number $k$ unit project, $A C_{i}$ represents the costs of the number $i$ activity, $A D_{k i}$ represents the amount of the consumed cost drivers of the number $i$ activity in the number $k$ unit project, $m$ is the amount of the unit projects.

\section{Project resource requirements and cost prediction}

According to the engineering drawings and the changes of engineering quantities, manage to predict the demand for different building products in the next stage of cost management, and calculate the total demand for different building products in the life cycle of construction through BIM software. And in accordance with the calculated product demand, based on the idea of activitybased costing "products consume activities and activities consume resources", forecast the demand for the material 
resources. At the same time, predict the cost of each activity cost base in the next stage of cost management and the total cost of the entire project in the future, based on the predicted cost of the resource.

\section{E. Pursuing "the zero inventory" in the material management}

The material supply of next phase is determined by comparing the forecasted demand for the material resources with the present supply of the resources, and the plan of material supply is adjusted according to the deviation, so here the supply chain is established which is motivated by the rear of supply chain, that is to say, the supply chain is motivated by the demand of kinds of materials, thus the zero inventory under the theory of lean management in materials management of the construction project is realized.

\section{F. Cost containment and construction project adjustment}

According to the calculated cost of the project, analyzing the implementation of cost of the construction project in order to find out the cause of deviations timely based on the statistical analysis methods, and adjusting the schedule of next stage of construction project and the plan of material supplement in accordance with the cause of deviations, to meet the requirement of cost, while analyzing, comparing and optimizing the activity chain during the phase of cost containment, and removing the invalid or non-value-added activities based on activitybased costing, in order to reengineer implementation processes of construction project, and achieve the target in the next stage of cost control loop.

\section{CONCLUSIONS}

The dynamic cost management in the process of construction project based on the activity-based costing is a continuous cycle process, that adjust the activities and the supply of resources of the next phase of construction project, according to the deviation between the budget cost and the actual cost, in order to control the project costs and achieve financial goals. It can help to raise the level of cost management of construction projects from the perspectives of strategy and activities, thereby enhancing the competitiveness of the project contractor. Distributing the cost of used resources into each product of construction projects on the basis of activity-based costing, realizes the accurate calculation of the cost of construction projects, and it is more scientific when comparing the actual cost with cost targets during different phases of the construction project. While the cost be refined, which can help to find out the exact cause of deviations and make timely adjustments in accordance with activities when analyzing the deviations of cost. Forecasting the cost of construction projects and demand of materials, based on activity-based costing, achieves beforehand control of the construction project cost and the lean management of kinds of materials. Meanwhile, cost management based on the activity-based costing supports to realize the organizational strategy, which gains value creation by eliminating non-value-added activities. Activity-based costing as an effective tool of cost management, it is worthwhile to be learned and applied by engineering contractors during the construction project, and with the development of information technology projects, activity-based costing will be more widely used in process of various construction projects.

\section{REFERENCES}

[1]Cooper, R. The Rise of Activity-Based Costing-Part One: What Is an Activity-Based Cost System? Journal of Cost Management, 1(2), pp.45-54,1988.

[2]Rui Zhan, BinRao, Wei Wu, The Application Study on Activitybased costing in Cigarette Manufacturing Industry, Accounting Research,(6), pp.59-65,July2006.

[3] Liang-HaiLei, Yu Zhang, The Application of Activity-based Costing in the Mortgage and Valuation Company of Real Estate, Friends of Accounting, (5), pp.52-53,2010.

[4]Gui-WenLiu, Yan-Juan Liang, The Application of Activity-based Costing in the Field of Real Estate Development. Co-Operative Economy \& Science, (384),pp.30-31,2010.

[5]Yi-JianSun, Ru-Fu Huang, Dai-Lin Chen, Hong-Nan Li, Gang Liu. Design and development of dynamic real state cost management system, China Civil Engineering Journal, 42(6), pp.121-125,2009.

[6]Wang Ai-dong. Enterprise logistic cost budget based on operation cost, Journal of Chang'an University (Social Science Edition), 10(1), pp.20-24, 2008.

[7] Cooper, R. The Rise of Activity-Based Costing-Part Two: When Do I Need an Activity-Based Cost System? Journal of Cost Management, 1(3), pp.41-58, 1988

[8] Cooper, R. The Rise of Activity-Based Costing-Part Three: How Many Cost Drivers Do You Need and How Do You Select Them? Journal of Cost Management, 1(4), pp.34-46,1988. 